\title{
Remote Academic Platforms in Times of a Pandemic
}

\author{
https://doi.org/10.3991/ijet.v16i21.25377 \\ Nathalia Ospina García ${ }^{1}$, Maria Fernanda Díaz Velásquez ${ }^{1}$ \\ Carlos Andrés Tavera Romero ${ }^{1(\varpi)}$, Jesús Hamilton Ortiz ${ }^{2}$, Osamah Ibrahim Khalaf ${ }^{3}$ \\ ${ }^{1}$ Universidad Santiago de Cali, Cali, Colombia \\ ${ }^{2}$ Closemobile R\&D Telecommunications LS, Fuenlabrada, España \\ ${ }^{3}$ Al-Nahrain University, Baghdad, Iraq \\ carlos.tavera00@usc.edu.co
}

\begin{abstract}
The pandemic has accelerated the use and development of video conferencing platforms due to COVID-19, and it is necessary to find an application that best suits our requirements. This article evaluates nine features of nine video conferencing applications to find the best choice. A detailed analysis has been conducted in this article using surveys to collect data from two samples at national and international level. The methodology followed is the CDIO methodology, a tool to address complex problems in four stages: conception, design, implementation, and operation. The primary aim of this paper is to examine which is the best livestreaming option according to the selected criteria, using, as references, well-known applications such as Jitsi, Zoom, Microsoft Teams, Google Meet, Big Blue Button, among others. An application of multicriteria analysis is also shown to support the evaluation of these platforms compared to the established criteria.
\end{abstract}

Keywords - livestreaming, online education, online meetings, video calls, elearning, COVID-19

\section{Introduction}

The research of "videostreaming" platforms seeks to reliably know which of these applications_-Jitsi, Zoom, Microsoft Teams, Google Meet, Big Blue Button, among others - is the best option in terms of quality, cost, and functionality to be used in the academic field, and thus, ensure that the most appropriate service is obtained according to the needs of both the educational entities (teachers) and users (students).

One of the main features for the users is the usability of learning tools; therefore, it becomes an important aspect to ensure that online learning is effective and useful for students [1]. E-learning is about learning and taking a step that helps to advance to a higher level of education [2]. Teaching and learning methods have gradually changed due to the COVID-19 pandemic. As a result, they directly create a difficult challenge for both students and educators [3].

A study conducted by the University of Cuenca, Ecuador, made a comparison between Zoom and Webex, where the conclusion was that both had the same level of 
usability even though Zoom was more attractive than Webex [4]. On the contrary, the University of Northampton, UK, conducted a study about Blackboard Collaborate, concluding that it was an easy-to-use and time-efficient technology, despite the technical issues; i.e., occasional delays and audio echo [5].

One of the most commonly used applications when it comes to videoconferencing or virtual meetings is Zoom, followed by Google Meet. Zoom VCT is a useful platform to enhance effective and synchronous e-learning [6]. This has been compared to other applications, looking for a different alternative for virtual meetings, even though it is still the main application that people use to communicate and conduct business through a screen while they need to maintain social distancing [7].

One thing that is suggested is that software companies should pay special attention to online security when implementing live videoconferencing software. This is to provide reliability to the user [8]. Yelena Chaiko et al. commented that the use of open source software is the best solution when it is implemented in many activity areas, concluding that the use of Big Blue Button is better than other applications, such as Zoom, because of its data vulnerability issue or Blackboard Collaborate due to its high cost [9]. On the contrary, a comparison study conducted between Microsoft Teams and Moodle highlights an advantage of MS Teams, since it does have audio and video calls that work in Skype as well and also enables desktop sharing [10]. Online platforms could potentially scale and improve both satisfaction and usability perceived by students over online platforms [11].

Virtual meetings have become an economical and environmentally friendly format for knowledge transfer and scientific communication [12]. Educational institutions are gradually migrating their applications to the cloud computing paradigm, because with the help of a security service, a better managed and more efficient use of resources can be executed [13].

The expected advances in technology for online education are not a need of the future but a need of the current era [14]. Socio-constructivist and cultural insights consider that learning is the result of the interaction between people and environment. This social process is the basis for collaborative learning. In this sense, the web, as a space for interaction, is a natural learning zone [15]. Some users consider virtual education as a favorable method, demonstrating that online learning is effective for the micro-subject of teaching [16].

The best advantage of the E-Learning format is the time saved in commuting to the university and the ease of participating and getting the basic and supplementary materials [17], although it is not all advantages, as explained by Maria Perifanou et al., all professors should receive advanced training on the use and exploitation of digital technologies in all their professional activities [18].

There has been a significant paradigm shift in the education system following the outbreak of COVID-19 [19]. Industry 4.0 also gains momentum due to the global pandemic, pushing companies to do something that they were already testing a long time ago but were unable to realize because many managers had not accepted the idea that it is possible to lead a team remotely, aided by tools and efficient communication[20]. Followed by Industry 4.0, a Japanese concept called Society 5.0 looms, which promotes a better life quality for people, based on technology that merges physical spaces with 
cyberspace [21]. The global pandemic COVID-19 has forced us to migrate to virtuality to be able to maintain social distancing, as a result of which applications, such as Zoom, Google Meet, Webex, among others, gain strength in both the educational and business areas.

Videoconferencing is used as a medium and technology in learning management based on group procedures where students can exchange their views [22]. Teaching faculties can also work from home effectively and get several opportunities related to their work, for their personal growth and also for the institutes [23].

A similar study was conducted at Sultan University, Riyadh, Saudi Arabia, assessing the satisfaction level of students regarding class lectures due to the online teaching during COVID-19 [24].

Virtual platforms have allowed us to be connected from a distance in much more efficient ways, but in terms of the area of medicine, a study was conducted where it was expressed that videoconferencing should be treated with caution in terms of privacy and data sharing, due to the criticism that Zoom had regarding its data vulnerability [25]. Moreover, the occurrence of new technologies in the health field is already more frequent [26].

In this context, a comparison is made among nine applications (Zoom, Big Blue Button, Jitsi, Google Meet, Microsoft Teams, Lifesize, Blackboard Collaborate, Skype, and Webex), where the aim is to identify which one best suits the user's needs in several pre-established cases based on technical and usage aspects (number of people in the meeting, meeting length, security, screen transmission, bandwidth capacity, audiovisual performance, integration with platforms, usability, and cost). A descriptive analysis for decision making will be conducted in four steps: (1) analyze the context of videostreaming applications for the definition of the universe of applications to be considered in this study; (2) design an instrument to measure the perception of people regarding the features of videostreaming platforms; (3) apply the instrument for the definition of which videostreaming application is suitable for the educational area; and (4) verify the results for the final presentation.

\section{$2 \quad$ Methodology}

The main objective of the study is to gather information on people's preferences about the technologies used. For this purpose, the CDIO methodology is used: conceive, design, implement, and operate.

In the conception stage, nine videostreaming applications are chosen to conduct a research comparing the features of each one, to identify the best application for the educational and/or work area.

For this study, in the second stage two scenarios are designed, the first one at national level where a survey was distributed to the community of the Universidad de Santiago de Cali, teachers, and students. The questionnaire consisted of 13 questions and was split in two parts, which were the preference of students and teachers for online classroom technology and the opinion of students and teachers on the selected criteria. In 
the second scenario at the international level, the different opinions of people from different countries of a universe, which in this case was Capterra, are collected.

In stage three, people's perception is analyzed, where different criteria are assessed at a national and international level to determine which application is the most appropriate for the educational community. A descriptive approach was considered for data analysis followed by a multicriteria analysis process to improve decision making.

In the operation stage, once the analysis process has been performed, the application with the highest score is obtained.

\section{Development}

In the first stage, a process of search and analysis of nine applications is conducted, evaluating them according to nine important criteria to identify which application is the most favorable for the educational community.

In the second stage, two scenarios are designed to obtain the views of people at national and international level: the first is done through a national survey for students and teachers of the Universdidad de Santiago de Cali; the second one is performed through a platform called Capterra, a platform designed for people to share their opinion about an application, helping others to make better decisions at an international level.

In the third stage, the comparison of criteria or paired alternatives between square matrices is implemented. Where $\mathrm{A}$ is an nxn, matrix, where ${ }^{a}{ }^{a} \mathrm{Z}+$. Where aij is the element $(i, j)$ of $A$, for $i=1,2 \ldots n$, and $, j=1,2 \ldots n$. We say that $A$ is a matrix of paired comparisons of $\mathrm{n}$ alternatives, if aij is the measure of the preferred alternative in row $\mathrm{i}$ when compared to the alternative in column $j$. When $i=j$, the value of aij will be equal to 1 , since the alternative is being compared with itself.

$$
\mathrm{A}=\left(\begin{array}{cccc}
1 & \mathrm{a}_{12} & \ldots & \mathrm{a}_{1 \mathrm{n}} \\
\mathrm{a}_{21} & 1 & \ldots & \mathrm{a}_{2 \mathrm{n}} \\
: & : & : & \vdots \\
\mathrm{a}_{\mathrm{n} 1} & \mathrm{a}_{\mathrm{n} 2} & \ldots & 1
\end{array}\right)
$$

Furthermore, it is also true that: aij.aji $=1$; i.e.,

$$
\mathrm{A}=\left(\begin{array}{cccc}
1 & \mathrm{a}_{12} & \ldots & \mathrm{a}_{1 \mathrm{n}} \\
1 / \mathrm{a}_{12} & 1 & \ldots & \mathrm{a}_{2 \mathrm{n}} \\
\vdots & : & : & \vdots \\
1 / \mathrm{a}_{1 \mathrm{n}} & 1 / \mathrm{a}_{2 \mathrm{n}} & \ldots & 1
\end{array}\right)
$$

Once the matrix of paired comparisons is developed, what is called the priority of each one of the elements under comparison can be calculated. The priority matrix is the one that summarizes the priorities for each alternative in terms of each criterion. For $\mathrm{m}$ criteria and $\mathrm{n}$ alternatives we have: 
Alternative 1
Alternative 2
$\ldots$
Alternative n $\left(\begin{array}{cccc}\text { Criterion 1 } & \text { Criterion 2 } & \ldots & \text { Criterion m } \\ \mathrm{P}_{11} & \mathrm{P}_{12} & \ldots & \mathrm{P}_{1 \mathrm{~m}} \\ \mathrm{P}_{21} & \mathrm{P}_{22} & \ldots & \mathrm{P}_{2 \mathrm{~m}} \\ \ldots & \ldots & \ldots & \ldots \\ \mathrm{P}_{\mathrm{n} 1} & \mathrm{P}_{\mathrm{n} 2} & \ldots & \mathrm{P}_{\mathrm{nm}}\end{array}\right)$

where Pij is the priority of alternative $i$ with respect to criterion $j$, for $i=1,2 \ldots n$; and $\mathrm{j}=1,2 \ldots \mathrm{m}$.

With the information collected in both scenarios (local and international), a multicriteria analysis is performed, evaluating in Saaty scale the criteria per scenario and each application per criterion as it can be observed in Tables 1 and 2 below.

Table 1. Saaty scale by criteria, at international level

\begin{tabular}{|l|c|c|c|c|c|c|c|c|c|}
\hline & C.P. & T. R. & S. & T.P. & A.B. & A.V. & I. & U. & C. \\
\hline C.P. & & 5 & 3 & $1 / 5$ & 1 & $1 / 3$ & 3 & $1 / 5$ & $1 / 3$ \\
\hline T.R. & $1 / 5$ & & $1 / 7$ & $1 / 9$ & $1 / 7$ & $1 / 7$ & $1 / 5$ & $1 / 9$ & $1 / 7$ \\
\hline S. & $1 / 3$ & 7 & & $1 / 7$ & $1 / 3$ & $1 / 5$ & 1 & $1 / 7$ & $1 / 5$ \\
\hline T.P. & 5 & 9 & 7 & & 5 & 3 & 7 & 1 & 3 \\
\hline A.B. & 1 & 7 & 3 & $1 / 5$ & & $1 / 3$ & 3 & $1 / 5$ & $1 / 3$ \\
\hline A.V. & 3 & 7 & 5 & $1 / 3$ & 3 & & 5 & $1 / 3$ & 1 \\
\hline I. & $1 / 3$ & 5 & 1 & $1 / 7$ & $1 / 3$ & $1 / 5$ & & $1 / 7$ & $1 / 5$ \\
\hline U. & 5 & 9 & 7 & 1 & 5 & 3 & 7 & & 3 \\
\hline C. & 3 & 7 & 5 & $1 / 3$ & 3 & 1 & 5 & $1 / 3$ & \\
\hline
\end{tabular}

Table 2. Saaty scale by criteria applications, in the case of Security Criterion

\begin{tabular}{|l|c|c|c|c|c|c|c|c|c|}
\hline & MT & Jitsi & Zoom & GM & Skype & BBB & Lifesize & Webex & BC \\
\hline MT & & 1 & 7 & 3 & 9 & 3 & 9 & 5 & 9 \\
\hline Jitsi & 1 & & 7 & 3 & 9 & 3 & 9 & 5 & 9 \\
\hline Zoom & $1 / 7$ & $1 / 7$ & & $1 / 7$ & 7 & $1 / 7$ & 7 & $1 / 5$ & 7 \\
\hline GM & $1 / 3$ & $1 / 3$ & 7 & & 7 & 1 & 7 & 3 & 9 \\
\hline Skype & $1 / 9$ & $1 / 9$ & $1 / 7$ & $1 / 7$ & & $1 / 7$ & 1 & $1 / 5$ & 1 \\
\hline BBB & $1 / 3$ & $1 / 3$ & 7 & 1 & 7 & & 7 & 3 & 7 \\
\hline Lifesize & $1 / 9$ & $1 / 9$ & $1 / 7$ & $1 / 7$ & 1 & $1 / 7$ & & 5 & 1 \\
\hline Webex & $1 / 5$ & $1 / 5$ & 5 & $1 / 3$ & 5 & $1 / 3$ & $1 / 5$ & & 5 \\
\hline BC & $1 / 9$ & $1 / 9$ & $1 / 7$ & $1 / 9$ & 1 & $1 / 7$ & 1 & $1 / 5$ & \\
\hline
\end{tabular}

In stage four, a hierarchical analysis process is conducted to determine which application is more favorable to people, resulting in the final matrix shown in Tables 3 and 4.

The global priority for each decision alternative is summarized in the column vector resulting from the product of the priorities matrix with the vector of priorities of the criteria. 


$$
\left(\begin{array}{cccc}
\mathrm{P}_{11} & \mathrm{P}_{12} & \ldots & \mathrm{P}_{1 \mathrm{~m}} \\
\mathrm{P}_{21} & \mathrm{P}_{22} & \ldots & \mathrm{P}_{2 \mathrm{~m}} \\
\ldots & \ldots & \ldots & \ldots \\
\mathrm{P}_{\mathrm{n} 1} & \mathrm{P}_{\mathrm{n} 2} & \ldots & \mathrm{P}_{\mathrm{nm}}
\end{array}\right)\left(\begin{array}{c}
\mathrm{P}_{1}^{\prime} \\
\mathrm{P}_{2}^{\prime} \\
\ldots \\
\mathrm{P}_{\mathrm{m}}^{\prime}
\end{array}\right)=\left(\begin{array}{c}
\mathrm{Pg}_{1} \\
\mathrm{Pg}_{2} \\
\ldots \\
\mathrm{Pg}_{\mathrm{n}}
\end{array}\right)
$$

n).

where Pgi is the global priority (regarding the global goal) of $i$ alternative $(i=1,2 \ldots$

Table 3. Comparison results at international level

\begin{tabular}{|l|c|c|c|c|c|c|c|c|c|c|c|}
\hline & $\begin{array}{c}\text { CP } \\
\text { Vector }\end{array}$ & $\begin{array}{c}\text { TR } \\
\text { Vector }\end{array}$ & $\begin{array}{c}\text { S } \\
\text { Vector }\end{array}$ & $\begin{array}{c}\text { TP } \\
\text { Vector }\end{array}$ & $\begin{array}{c}\text { AB } \\
\text { Vector }\end{array}$ & $\begin{array}{c}\text { AV } \\
\text { Vector }\end{array}$ & $\begin{array}{c}\mathbf{I} \\
\text { Vector }\end{array}$ & $\begin{array}{c}\text { U } \\
\text { Vector }\end{array}$ & $\begin{array}{c}\text { C } \\
\text { Vector }\end{array}$ & $\begin{array}{c}\text { Criteria } \\
\text { Vector }\end{array}$ & $\begin{array}{c}\text { Result } \\
\text { Vector }\end{array}$ \\
\hline MT & 0,22 & 0,03 & 0,25 & 0,11 & 0,11 & 0,26 & 0,19 & 0,03 & 0,07 & 0,06 & $12 \%$ \\
\hline Jitsi & 0,22 & 0,3 & 0,25 & 0,05 & 0,11 & 0,13 & 0,19 & 0,19 & 0,24 & 0,02 & $15 \%$ \\
\hline Zoom & 0,09 & 0,2 & 0,07 & 0,24 & 0,18 & 0,13 & 0,05 & 0,19 & 0,04 & 0,04 & $16 \%$ \\
\hline GM & 0,13 & 0,3 & 0,14 & 0,16 & 0,07 & 0,05 & 0,19 & 0,19 & 0,16 & 0,26 & $15 \%$ \\
\hline Skype & 0,02 & 0,03 & 0,02 & 0,03 & 0,2 & 0,13 & 0,02 & 0,03 & 0,04 & 0,07 & $5 \%$ \\
\hline BBB & 0,02 & 0,03 & 0,14 & 0,05 & 0,09 & 0,07 & 0,12 & 0,06 & 0,24 & 0,13 & $9 \%$ \\
\hline Lifesize & 0,02 & 0,03 & 0,05 & 0,1 & 0,18 & 0,13 & 0,19 & 0,19 & 0,11 & 0,04 & $13 \%$ \\
\hline Webex & 0,21 & 0,03 & 0,07 & 0,17 & 0,04 & 0,07 & 0,02 & 0,09 & 0,07 & 0,26 & $11 \%$ \\
\hline BC & 0,07 & 0,03 & 0,02 & 0,11 & 0,03 & 0,04 & 0,02 & 0,03 & 0,02 & 0,13 & $5 \%$ \\
\hline
\end{tabular}

In the national scenario, the survey conducted over the course of one week yielded 399 responses showing the preference of students and teachers regarding the assessed applications.

In terms of the assessed features considered the most important ones in a videostreaming application, respondents were asked to rank them from least important to most important by rating them from 1 to 10 ; a multicriteria analysis was performed based on the respondents' answers, thus obtaining the result shown in Figure 1.

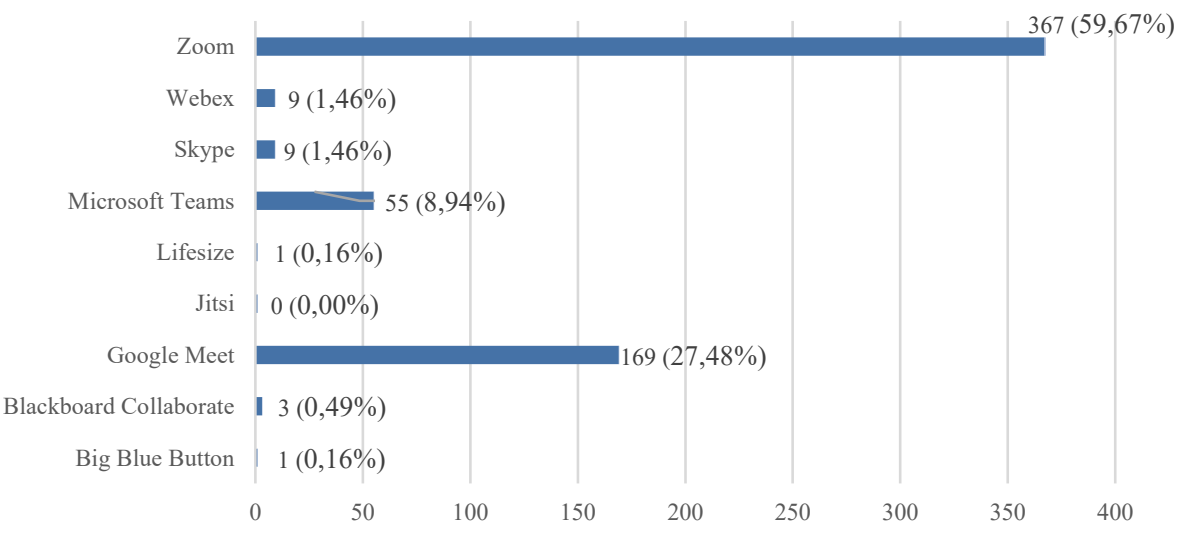

Fig. 1. Chart of assessed applications at national level 
Table 4. Results of the comparison at a local level

\begin{tabular}{|l|c|c|c|c|c|c|c|c|c|c|c|}
\hline & $\begin{array}{c}\text { CP } \\
\text { Vector }\end{array}$ & $\begin{array}{c}\text { TR } \\
\text { Vector }\end{array}$ & $\begin{array}{c}\text { S } \\
\text { Vector }\end{array}$ & $\begin{array}{c}\text { TP } \\
\text { Vector }\end{array}$ & $\begin{array}{c}\text { AB } \\
\text { Vector }\end{array}$ & $\begin{array}{c}\mathbf{A V} \\
\text { Vector }\end{array}$ & $\begin{array}{c}\mathbf{I} \\
\text { Vector }\end{array}$ & $\begin{array}{c}\mathbf{U} \\
\text { Vector }\end{array}$ & $\begin{array}{c}\mathbf{C} \\
\text { Vector }\end{array}$ & $\begin{array}{c}\text { Criteria } \\
\text { Vector }\end{array}$ & $\begin{array}{c}\text { Result } \\
\text { Vector }\end{array}$ \\
\hline MT & 0,22 & 0,03 & 0,25 & 0,11 & 0,11 & 0,26 & 0,19 & 0,03 & 0,07 & 0,03 & $13 \%$ \\
\hline Jitsi & 0,22 & 0,30 & 0,25 & 0,05 & 0,11 & 0,13 & 0,19 & 0,19 & 0,24 & 0,30 & $21 \%$ \\
\hline Zoom & 0,09 & 0,20 & 0,07 & 0,24 & 0,18 & 0,13 & 0,05 & 0,19 & 0,04 & 0,12 & $14 \%$ \\
\hline GM & 0,13 & 0,30 & 0,14 & 0,16 & 0,07 & 0,05 & 0,19 & 0,19 & 0,16 & 0,03 & $18 \%$ \\
\hline Skype & 0,02 & 0,03 & 0,02 & 0,03 & 0,20 & 0,13 & 0,02 & 0,03 & 0,04 & 0,22 & $7 \%$ \\
\hline BBB & 0,02 & 0,03 & 0,14 & 0,05 & 0,09 & 0,07 & 0,12 & 0,06 & 0,24 & 0,07 & $9 \%$ \\
\hline Lifesize & 0,02 & 0,03 & 0,05 & 0,10 & 0,18 & 0,13 & 0,19 & 0,19 & 0,11 & 0,15 & $11 \%$ \\
\hline Webex & 0,21 & 0,03 & 0,07 & 0,17 & 0,04 & 0,07 & 0,02 & 0,09 & 0,07 & 0,02 & $5 \%$ \\
\hline BC & 0,07 & 0,03 & 0,02 & 0,11 & 0,03 & 0,04 & 0,02 & 0,03 & 0,02 & 0,05 & $3 \%$ \\
\hline
\end{tabular}

\section{Results}

For the first stage, it was decided to identify different videostreaming applications in the work and educational sectors, finding as options to be assessed the following ones: Microsoft Teams, Zoom, Google Meet, Skype, Jitsi, Webex, Big Blue Button, Blackboard Collaborate, and Lifesize.

For the second stage, a survey was designed at the Universidad de Santiago de Cali to identify the opinion of students and teachers about the videostreaming applications, rating them according to their performance in different previously established criteria. The Capterra application was also used to know the views of people at the international level, taking into account these same criteria.

In the third stage, when the multicriteria analysis was implemented, a criteria evaluation by scenario and by application was obtained, generating the data shown in Tables 3 and 4.

For the fourth stage, in the international scenario, Table 3 shows that the most favorable platforms for users are Zoom followed by Google Meet and Jitsi. In the local scenario, Chart 1 shows that teachers and students prefer Zoom followed by Google Meet and Microsoft Teams, but in the multicriteria analysis, shown in Table 4, it can be observed that the Jitsi platform is more beneficial for users due to its cost/benefit ratio, because as it is an open source software, it is free and adaptable to specific needs.

\section{Discussion}

In the first stage, as there is a universe of applications for videostreaming, only the nine most popular ones were chosen, although there are others besides the nine assessed in this article, such as Adobe Connect, an application for online meetings, which offers the basic features of a videostreaming application but is already used in some educational institutions; another option to be considered is StreamYard, which offers very similar functions in terms of capabilities, with positive features for live video streaming and easy integration with social media. 
In the design stage, a survey of 13 questions was performed at a national level over the course of 8 days, resulting in 609 answers. With a security question, the answers that were correctly answered were filtered, reaching a total of 399 correct answers. At the international level, the positive and negative opinions of 225 people from several countries in America were analyzed.

A hierarchical analysis process was implemented in the third stage to achieve better decision making [27], based on the answers obtained in the surveys conducted, and to validate the results, this procedure was performed in an application called Priority Estimation Tool (APH) to obtain an appropriate result.

For the fourth stage, at the international level, it is evident that, although the Microsoft Teams platform has one of the best performances in terms of price, it is below Lifesize and only slightly above the elite platform of Cisco Webex, and it also proves that the pass of the years has not been favorable to Skype. The user experience is more relevant in the "casual" audience because despite being in the lowest rank, the "Blackboard Collaborate" application mainly has educational use.

However, at the local level, although the analysis shows that Jitsi is the best option, Google Meet provides better integration with complete suites such as G-Suite; Zoom has similar features but its high cost puts it below the aforementioned platforms. Microsoft Teams offers full integration with the Office suite, plus its great screen transmission capacity and high quality audio and video which makes it a good fit. Lifesize, on the contrary, has extensive integration with Microsoft and better bandwidth management, only surpassed by Skype, although both of them have a lower participant capacity than Webex, and Big Blue Button as it is also an open source option offers good security for a free system, while Blackboard Collaborate despite its high cost and focus on the educational area is not as user-friendly.

\section{Conclusion}

In the first stage, an analysis of the nine applications chosen for this article was conducted, based on nine criteria considered important in an application, meeting the goal of analyzing the context of videostreaming applications for the definition of the universe of applications to be considered in this study.

By conducting the survey and reading several people's opinions, in the second stage it was possible to demonstrate at national and international levels which videostreaming application of those selected for the study was the most favorable for the educational and/or business area, thus fulfilling the goal of designing an instrument to measure people's perception regarding the features of videostreaming platforms.

In the third stage, with the results of the survey and the different views collected, an analysis process was applied where a comparison of the applications selected for this study was made, deciding which videostreaming application was more suitable for the educational area, thus achieving the third goal.

Experts criticize Zoom for its weak privacy and continue finding vulnerabilities, which include connecting to another person's conversations, transferring data from an iOS app to Facebook, lack of end-to-end encryption, the ability to hijack the Windows 
account password and gain full access to macOS [28]. Despite this, majority of people still prefer the Zoom platform for their meetings, whether they are virtual classrooms or business meetings. This is because it is a user-friendly, easy-to-use platform. Following Zoom is Jitsi. As a result of the study that was conducted, the two platformsZoom and Jitsi-apart from being the most preferred by people, are the most suitable for use in both the educational and business areas, not only because of its ease of use but also because their cost is convenient for those who want to acquire the platform, thus achieving the ultimate goal.

\section{$7 \quad$ Acknowledgment}

This research has been funded by Dirección General de Investigaciones of Universidad de Santiago de Cali under call No. 01-2021.

\section{$8 \quad$ References}

[1] D. Pal and V. Vanijja, "Perceived usability evaluation of Microsoft Teams as an online learning platform during COVID-19 using system usability scale and technology acceptance model in India," Child. Youth Serv. Rev., vol. 119, no. July, p. 105535, 2020, https://doi.org/10.1016/j.childyouth.2020.105535

[2] L. K. Butola, "E-learning-a new trend of learning in 21st century during COVID-19 pandemic," Indian J. Forensic Med. Toxicol., vol. 15, no. 1, pp. 422-426, 2021, https://doi.org/10.37506/ijfmt.v15i1.13443

[3] R. M. Saidi, A. A. Sharip, N. Z. Abd Rahim, Z. A. Zulkifli, and S. M. Md Zain, "Evaluating Students' Preferences of Open and Distance Learning (ODL) Tools," Procedia Comput. Sci., vol. 179, no. 2019, pp. 955-961, 2021, https://doi.org/10.1016/j.procs.2021.01.085

[4] O. Parra and M. Granda, "Evaluating the Meeting Solutions Used for Virtual Classes in Higher Education during the COVID-19 Pandemic," vol. 2, no. Visigrapp, pp. 190-197, 2021, https://doi.org/10.5220/0010258201900197

[5] T. Hart, D. Bird, and R. Farmer, "Using blackboard collaborate, a digital web conference tool, to support nursing students placement learning: A pilot study exploring its impact," Nurse Educ. Pract., vol. 38, no. June 2018, pp. 72-78, 2019, https://doi.org/10.1016/j.nepr. $\underline{2019.05 .009}$

[6] C. B. Mpungose, "Lecturers' reflections on use of Zoom video conferencing technology for e-learning at a South African university in the context of coronavirus," African Identities, vol. 00, no. 00, pp. 1-17, 2021, https://doi.org/10.1080/14725843.2021.1902268

[7] A. Mahr, M. Cichon, S. Mateo, C. Grajeda, and I. Baggili, "Zooming into the pandemic! A forensic analysis of the Zoom Application," Forensic Sci. Int. Digit. Investig., vol. 36, p. 301107, 2021, https://doi.org/10.1016/j.fsidi.2021.301107

[8] N. N. Long and B. H. Khoi, "The Intention to Study Using Zoom During the SARSCoV-2 Pandemic," Int. J. Emerg. Technol. Learn., vol. 15, no. 21, pp. 195-216, 2020, https://doi.org/10.3991/ijet.v15i21.16777

[9] Y. Chaiko, N. Kunicina, A. Patlins, and A. Zhiravetska, "Advanced practices: Web technologies in the educational process and science," 2020 IEEE 61st Annu. Int. Sci. Conf. Power Electr. Eng. Riga Tech. Univ. RTUCON 2020 - Proc., 2020, https://doi.org/10.1109/ rtucon51174.2020.9316567 
[10] M. Krasna and I. Pesek, "Influence of Moodle and MS Teams on teaching-learning-studying (TLS) processes," 2020 43rd Int. Conv. Information, Commun. Electron. Technol. MIPRO 2020 - Proc., pp. 612-616, 2020, https://doi.org/10.23919/mipro48935.2020.9245356

[11] R. S. Al-Maroof, M. T. Alshurideh, S. A. Salloum, A. Q. M. AlHamad, and T. Gaber, "Acceptance of Google Meet during the Spread of Coronavirus by Arab University Students," Informatics, vol. 8, no. 2, p. 24, 2021, https://doi.org/10.3390/informatics 8020024

[12] G. Roos, J. Oláh, R. Ingle, R. Kobayashi, and M. Feldt, "Online conferences - Towards a new (virtual) reality," Comput. Theor. Chem., vol. 1189, no. August, p. 112975, 2020, https://doi.org/10.1016/j.comptc.2020.112975

[13] C. A. Tavera Romero, J. H. Ortiz, O. I. Khalaf, and W. Montilla Ortega, "Software Architecture for Planning Educational Scenarios by Applying an Agile Methodology," Int. J. Emerg. Technol. Learn., vol. 16, no. 08, p. 132, Apr. 2021, https://doi.org/10.3991/ ijet.v16i08.20603

[14] B. Vadivel, M. Mathuranjali, and N. R. Khalil, "Online teaching: Insufficient application of technology," Mater. Today Proc., no. xxxx, pp. 1-5, 2021, https://doi.org/10.1016/j.matpr. $\underline{2021.01 .454}$

[15] M. Á. Herrera-Pavo, “Collaborative learning for virtual higher education," Learn. Cult. Soc. Interact., vol. 28, no. April 2020, 2021, https://doi.org/10.1016/j.lcsi.2020.100437

[16] V. Roza, "Incorporating both Zoom and YouTube in Micro Teaching Class during the Covid-19 Pandemic: An Effectiveness Investigation," J. Phys. Conf. Ser., vol. 1779, no. 1, 2021, https://doi.org/10.1088/1742-6596/1779/1/012033

[17] L. V. Sharakhina and A. A. Chugunova, "Digital platforms and applications for "online and offline copyrighting' discipline in on-line education format," Proc. 2020 IEEE Int. Conf. "Quality Manag. Transp. Inf. Secur. Inf. Technol. IT QM IS 2020, pp. 605-608, 2020, https://doi.org/10.1109/itqmis51053.2020.9322892

[18] M. Perifanou, A. A. Economides, and K. Tzafilkou, "Teachers ' Digital Skills Readiness During COVID-19 Pandemic," pp. 238-251. https://doi.org/10.3991/ijet.v16i08.21011

[19] A. K. Kansal, J. Gautam, N. Chintalapudi, S. Jain, and G. Battineni, "Google Trend Analysis and Paradigm Shift of Online Education Platforms during the COVID-19 Pandemic," vol. 2019, pp. 418-428, 2021. https://doi.org/10.3390/idr13020040

[20] C. A. T. Romero, D. F. Castro, J. H. Ortiz, O. I. Khalaf, and M. A. Vargas, "Synergy between Circular Economy and Industry 4.0: A Literature Review," Sustainability, vol. 13, no. 8, p. 4331, Apr. 2021, https://doi.org/10.3390/su13084331

[21] C. Narvaez Rojas, G. A. Alomia Peñafiel, D. F. Loaiza Buitrago, and C. A. Tavera Romero, "Society 5.0: A Japanese Concept for a Superintelligent Society," Sustainability, vol. 13, no. 12, p. 6567, 2021, https://doi.org/10.3390/su13126567

[22] N. Nonthamand, "Guideline to develop an instructional design model using video conference in open learning," Int. J. Emerg. Technol. Learn., vol. 15, no. 3, pp. 140-155, 2020, https://doi.org/10.3991/ijet.v15i03.10842

[23] P. Yadav, S. Ramesh, M. Suji, L. B. Thomas, and S. Fernandis, "Opportunities and obstacles faced during work from home in teaching faculties," Indian J. Forensic Med. Toxicol., vol. 14, no. 4, pp. 3704-3711, 2020, https://doi.org/10.37506/ijfmt.v14i4.12206

[24] N. M. Almusharraf and S. H. Khahro, "Students' Satisfaction with Online Learning Experiences during the COVID-19 Pandemic," Int. J. Emerg. Technol. Learn., vol. 15, no. 21, pp. 246-267, 2020, https://doi.org/10.3991/ijet.v15i21.15647

[25] M. Lieux, C. Sabottke, E. R. Schachner, C. Pirtle, R. Danrad, and B. Spieler, "Online conferencing software in radiology: Recent trends and utility," Clin. Imaging, vol. 76, no. February, pp. 116-122, 2021, https://doi.org/10.1016/j.clinimag.2021.02.008 
[26] C. A. Tavera, J. H. Ortiz, O. I. Khalaf, D. F. Saavedra, and T. H. H. Aldhyani, "Wearable Wireless Body Area Networks for Medical Applications," Comput. Math. Methods Med., vol. 2021, pp. 1-9, Apr. 2021, https://doi.org/10.1155/2021/5574376

[27] C. A. T. Romero, J. H. Ortiz, O. I. Khalaf, and A. R. Prado, "Web application commercial design for financial entities based on business intelligence," Comput. Mater. Contin., vol. 67, no. 3, 2021, https://doi.org/10.32604/cmc.2021.014738

[28] J. Caiko, A. Patlins, A. Nurlan, and V. Protsenko, "Video-conference Communication Platform Based on WebRTC Online meetings," 2020 IEEE 61st Annu. Int. Sci. Conf. Power Electr. Eng. Riga Tech. Univ. RTUCON 2020 - Proc., 2020, https://doi.org/10.1109/ rtucon51174.2020.9316605

\section{Authors}

Nathalia Ospina García is a System Engineering of the Universidad Santiago de Cali, Colombia.

Maria Fernanda Díaz Velásquez from Research Group GIEIAM in Faculty of Engineering of the Universidad Santiago de Cali, Colombia.

Carlos Andrés Tavera Romero from Research Group COMBA I+D in Faculty of Engineering of the Universidad Santiago de Cali, Colombia.

Jesús Hamilton Ortiz is CEO of Closemobile R\&D Telecommunications LS, Fuenlabrada, España.

Osamah Ibrahim Khalaf from Al-Nahrain University, Al-Nahrain Nanorenewable Energy Research Center, Baghdad, Iraq.

Article submitted 2021-07-09. Resubmitted 2021-08-11. Final acceptance 2021-08-13. Final version published as submitted by the authors. 